\title{
Reversible liver damage induced by Paroxetine in a patient with major depressive disorder
}

I Donas-Boto ${ }^{1}$ MF Urzal ${ }^{1}$, R Moura ${ }^{1}$, B Silva ${ }^{1}$

1 - Department of Psychiatry and Mental Health, Centro Hospitalar de Lisboa Ocidental

\section{Objectives}

To discuss the risk of liver damage in patients treated with paroxetine.

\section{Background and aims}

Drug-induced liver injury (DILI) is a rare adverse effect of paroxetine, a selective serotonin reuptake inhibitor (SSRI). The authors report an illustrative clinical case and present a brief review of the relevant literature.

\section{Materials and methods}

"Pubmed" database was searched using the terms "paroxetine" and "hepatotoxicity". Relevant data from the patient's medical record was collected.

\section{Results}

\section{ఠా, 79 years old, Major Depressive Disorder}

Treated with:

- Paroxetine 40mg/day (started 7 months before)

- Quetiapine SR 50mg/day, mirtazapine $30 \mathrm{mg} /$ day and alprazolam $0.5 \mathrm{mg} /$ day (recently started)

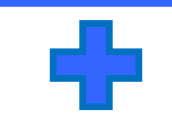

\begin{tabular}{|llll|}
\hline Nausea $\quad+\quad$ Vomiting $\quad+\quad$ Abdominal discomfort \\
\hline
\end{tabular}

GGT - 396IU/L

\section{Laboratory tests:}

ALT, AST - 198IU/L, 86IU/L Total bilirrubin $-1.6 \mathrm{mg} / \mathrm{dL}$ Alkaline phosphatase - 401IU/L

Viral hepatitis serological tests - negative

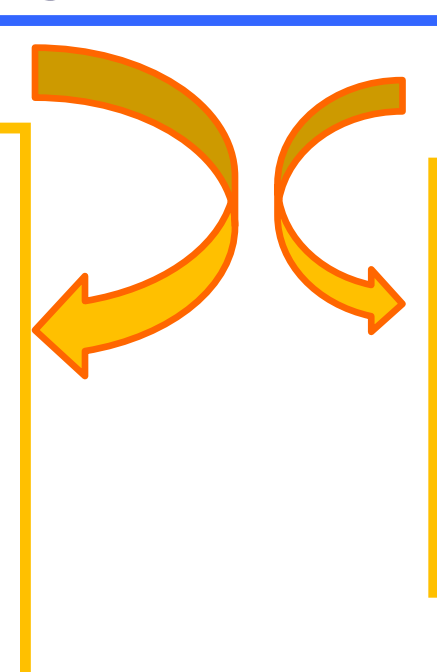

\[ \text { Imagiology tests: } \]
Liver ultrasound
Endoscopic retrograde cholangio-pancreatography
NORMAL

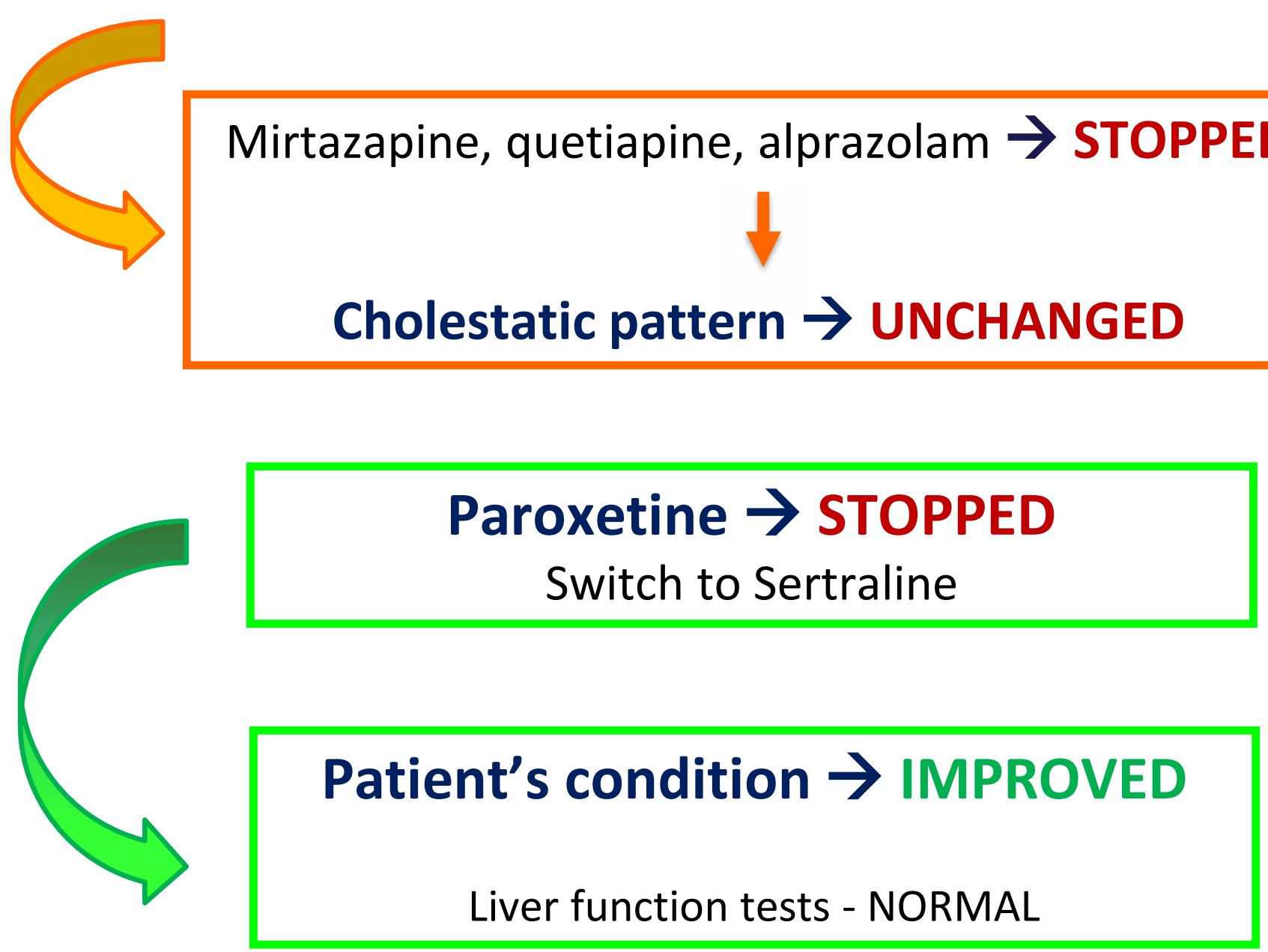

Discussion and key notes

Paroxetine had the largest number of cases of DILI within the SSRI class

Liver damage is in most cases idiosyncratic, unpredictable and unrelated to drug dosage.

PROMPT RECOGNITION of liver injury and EARLY WITHDRAWAL are ESSENTIAL 